\title{
DETERMINAN LOYALITAS KONSUMEN SITUS TOKOPEDIA DI JAKARTA
}

\author{
Alfan Kurniawan John Franklyn dan Cokki \\ Program Studi Manajemen Fakultas Ekonomi dan Bisnis \\ Universitas Tarumanagara, Jakarta \\ E-Mail: alfan.115170310@stu.untar.ac.id
}

\begin{abstract}
The purpose of this study was to examine the effect of website quality on customer loyalty, directly and indirectly through trust and customer satisfaction. The population of this study was 140 Tokopedia website customers in Jakarta. The data collection technique used is convenience sampling by distributing online questionnaires. Data analysis used the Partial Least Square-Structural Equation Modeling (PLS-SEM) technique. The results of this study are website quality, trust, and customer satisfaction affect customer loyalty directly and indirectly.
\end{abstract}

Keywords: Website quality, trust, customer satisfaction, customer loyalty

Abstrak: Tujuan dari penelitian ini adalah untuk menguji pengaruh dari variabel kualitas situs terhadap variabel loyalitas konsumen melalui variabel kepercayaan dan kepuasan konsumen. Populasi dari penelitian ini adalah 140 pengguna situs Tokopedia di Jakarta yang dipilih dengan menggunakan convenience sampling. Data diambil dengan menggunakan kuesioner daring dan diolah menggunakan Partial Least Square-Structural Equation Modeling (PLS-SEM). Hasil penelitian ini adalah variabel loyalitas konsumen dipengaruhi secara positif oleh variabel kualitas situs, kepercayaan, dan kepuasan konsumen

Kata Kunci: Kualitas situs, kepercayaan, kepuasan konsumen, loyalitas konsumen.

\section{LATAR BELAKANG}

Industri ecommerce berkembang pesat di dunia, termasuk Indonesia belakangan ini. Salah satu marketplace terbesar di Indonesia saat ini adalah Tokopedia. Seiring dengan perkembangan teknologi, semakin banyak pula pesaing yang tumbuh dan lahir pada industri marketplace ini. Oleh karena itu Tokopedia harus selalu dapat berkembang sehingga dapat terus bertahan.

Untuk dapat terus bertahan, sebuah perusahaan harus dapat mempertahankan dan terus meningkatkan jumlah dan kualitas konsumen yang ada pada bisnis tersebut. Dalam kasus perusahaan eommerce marketplace, hal ini dapat dinilai berdasarkan retailer yang ada di marketplace, dan juga konsumen atau pembeli yang bertransaksi di platform tersebut.

Loyalitas merujuk pada sikap menyukai terhadap suatu brand dan juga pembelian berulang. Loyalitas konsumen secara tidak langsung menentukan kelangsungan hidup perusahaan. Oleh karena itu Tokopedia harus dapat mempertahankan hubungan jangka 
panjang terhadap retailer dan pembeli ini. Penelitian sebelumnya belum ada yang membahas sekaligus secara utuh seluruh variabel yang diteliti pada penelitian ini (kualitas situs, kepercayaan, kepuasan konsumen, loyalitas konsumen). Penelitian ini dilakukan agar dapat mengetahui seberapa besar pengaruh kualitas situs sebuah platform marketplace, kepercayaan terhadap platform, dan kepuasan konsumen platform tersebut berpengaruh pada loyalitas konsumen yang dimiliki.

\section{KAJIAN TEORI}

Theory of Planned Behavior (TPB) merupakan landasan teori untuk melihat sikap yang dapat mempengaruhi perilaku seseorang. Ajzen (1991) menyatakan bahwa perilaku dipengaruhi oleh niat seseorang yang berkaitan dengan perilaku tertentu. Loyalitas konsumen adalah kecendrungan konsumen untuk membeli ulang melalui perilaku yang bisa diukur dan akan mempengaruhi penjualan brand secara langsung (Worthington et al., 2010). Pada dasarnya loyalitas dapat dikatakan sebagai sebuah perilaku seseorang yang dilakukan berulang untuk menggunakan sebuah produk atau servis tertentu.

Kualitas situs merujuk pada kualitas dan performa keseluruhan sebuah situs dan yang mana adalah sebuah pengukuran seberapa baik nya desain dan proses melalui kualitas seperti kesederhanaan, kehalusan, dan ke efektifan (Al Debei et al., 2014). Definisi kepercayaan menurut Putra \& Keni (2020) yaitu suatu ikatan hubungan pelanggan dengan sebuah merek yang dilandaskan atas rasa aman dan kepercayaan bahwa merek tersebut dapat diandalkan dalam pemenuhan kepentingan dan kebutuhan pelanggan

Kepuasan konsumen adalah tindakan pasca pembelian yang menunjukkan perasaan konsumen setelah menggunakan produk atau servis tertentu (Ozkan et al., 2019). Loyalitas konsumen adalah komitmen pada pelanggan untuk membeli kembali serta terus menjadi langganan dimasa yang akan datang (Keni \& Sandra, 2021).

\section{Kaitan antara variabel kualitas situs, kepercayaan, kepuasan konsumen, dan loyalitas konsumen.}

Filieri (2015) meneliti mengenai faktor yang mempengaruhi kepercayaan terhadap website perjalanan Trip Advisor pada mahasiswa dan staf akademik pada dua universitas di Irlandia dan Inggris. Hasil penelitian menunjukkan bahwa kualitas situs memiliki pengaruh positif terhadap kepercayaan. Terdapat juga penelitian Kim (2013) mengenai faktor pembentuk kepercayaan pada pengguna s-commerce di Korea dan penelitian Polites (2012) terhadap pengunjung situs hotel InterContinental Hotels Group (IHG), menunjukkan bahwa kualitas situs memiliki pengaruh positif terhadap kepuasan konsumen.

Kincl \& Strach (2012) pada penelitiannya mengenai pengaruh kualitas situs terhadap kepuasan dengan responden mahasiswa dari sekolah bisnis di Republik Ceko. Giao et al (2019) pada penelitiannya terhadap dampak kualitas situs terhadap loyalitas konsumen di Vietnam dan juga penelitian O'Cass dan Carlson (2012) terhadap para konsumen belanja online di Australia yang menunjukkan bahwa kualitas situs memiliki pengaruh positif terhadap loyalitas konsumen

Omoregie et al (2018) dalam penelitiannya mengenai konsumen bank retail di Ghana menunjukkan bahwa kepercayaan memiliki pengaruh positif terhadap kepuasan konsumen 
dan loyalitas konsumen. Penelitian Selim et al (2019) terhadap perusahaan manufaktur dan logistik halal di Malaysia juga menunjukkan bahwa kepercayaan memiliki pengaruh posiitf terhadap kepuasan.

Slack \& Singh (2020) dalam penelitiannya pada supermarket di Fiji menunjukkan bahwa kepuasan konsumen memiliki pengaruh positif terhadap loyalitas konsumen. Kataria \& Saini (2019) dalam penelitiannya mengenai loyalitas konsumen pasta gigi di New Delhi menunjukkan bahwa kepuasan konsumen memiliki pengaruh positif pada loyalitas konsumen.

Berdasarkan kaitan antar variabel diatas, maka model penelitian ini sebagai berikut:

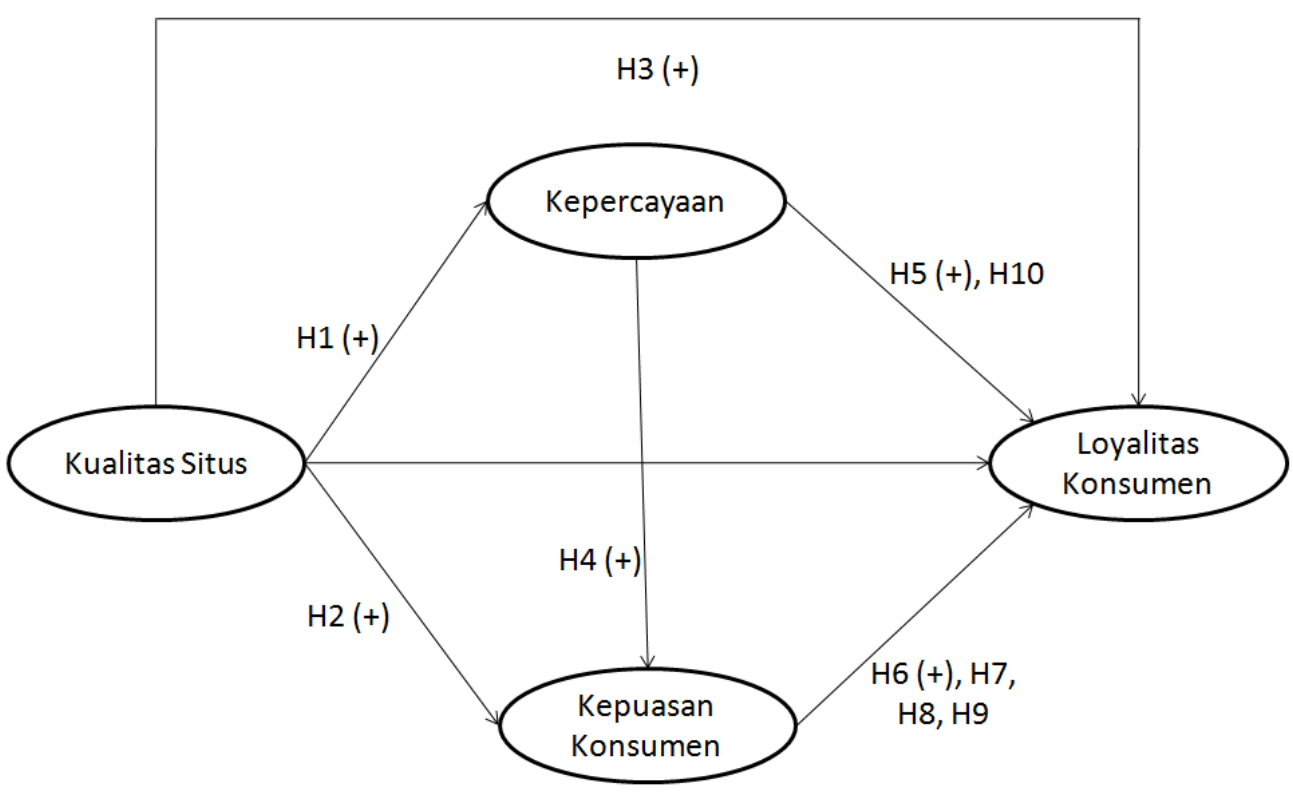

Gambar 1

\section{Model Penelitian}

Berdasarkan gambar di atas, hipotesis yang diajukan dalam penelitian ini adalah sebagai berikut:

H1: Kualitas situs memiliki pengaruh positif terhadap kepercayaan konsumen

H2: Kualitas situs memiliki pengaruh positif terhadap kepuasan konsumen

H3: Kualitas situs memiliki pengaruh positif terhadap loyalitas konsumen

H4: Kepercayaan konsumen memiliki pengaruh positif terhadap kepuasan konsumen

H5: Kepercayaan konsumen memiliki pengaruh positif terhadap loyalitas konsumen

H6: Kepuasan konsumen memiliki pengaruh positif terhadap loyalitas konsumen 
H7: Kepercayaan memiliki pengaruh positif terhadap loyalitas konsumen melalui kepuasan konsumen

H8: Kualitas situs memiliki pengaruh positif terhadap loyalitas konsumen melalui kepercayaan dan kepuasan konsumen

H9: Kualitas situs memiliki pengaruh positif terhadap loyalitas konsumen melalui kepuasan konsumen

H10: Kualitas situs memiliki pengaruh positif terhadap loyalitas konsumen melalui kepercayaan

\section{METODOLOGI}

Penelitian ini menggunakan jenis penelitian deskriptif dengan menggunakan data time cross-sectional karena melibatkan pengumpulan informasi hanya sekali dari sampel tertentu (Malhotra, 2010). Populasi dalam penelitian ini adalah Populasi dalam penelitian ini adalah konsumen situs Tokopedia di Jakarta, teknik pengambilan sampel yang digunakan adalah convenience sampling. Teknik ini digunakan karena sampel yang dipilih adalah subkelompok dari populasi yang terpilih dari proyek penelitian (Sekaran \& Bougie, 2013).

Teknik pengumpulan data menggunakan kuesioner yang disebar secara online. Kualitas situs diukur dengan menggunakan 6 indikator yang diadopsi dari penelitian Jeon \& Jeong (2017), dan Madariaga et al (2019). Kepercayaan diukur dengan menggunakan 6 indikator yang diadopsi penelitian dari Madariaga, et al. (2019), Al-Debei, et. al. (2015) Akhgari et al (2018) dan Chang \& Hung (2018). Kepuasan konsumen diukur dengan menggunakan 5 indikator yang diadopsi dari penelitian Jeon \& Jeong (2017), Limbu et al. (2011), dan Chang \& Hung (2018). Loyalitas konsumen diukur dengan 6 indikator yang diadopsi dari penelitian Madariaga et al. (2019), Jeon \& Jeong (2017), dan Limbu et al. (2011)

Teknik analisis data yang digunakan adalah Partial Least Square-Structural Equation Modeling (PLS-SEM) yang diolah dengan alat SmartPLS yang terdiri dari dua analisis yaitu outer model yang terdiri dari validitas dan reabilitas serta inner model pada bagian analisis data

\section{HASIL ANALISIS DATA}

Responden pada penelitian terdiri dari 104 orang pria (74\%) dan 36 wanita (26\%). Usia responden mayoritas adalah usia 21-30 tahun dengan jumlah total 134 responden (95\%). Pendidikan terakhir yang dominan adalah SMA/SMK dengan total responden 130 orang (93\%) dan pekerjaan yang dominan adalah pelajar/mahasiswa sebanyak 132 orang (94\%).

Berdasarkan informasi responden dalam hal usia, pendidikan terakhir dan pekerjaan dapat diartikan bahwa pengisian kuesioner telah diisi oleh orang yang sudah cukup usia untuk memahami pernyataan dengan baik.

Analisis validitas konvergenmenunjukkan bahwa setiap variabel lolos uji karena memiliki nilai $A V E$ lebih dari 0.50 (Hair et al., 2011; Tabel 1). Kemudian hasil analisis reliabilitas konsistensi internal menunjukkan bahwa setiap variabel lolos uji karena memiliki nilai composite reliability lebih dari 0.7 (Hair et al., 2019; Tabel 4) 
Franklyn dan Cokki: Determinan Loyalitas Konsumen...

Tabel 1. Validitas Konvergen

\begin{tabular}{|l|l|}
\hline \multicolumn{1}{|c|}{ Variabel/Dimensi } & AVE \\
\hline Kualitas Situs & 0.590 \\
\hline \multicolumn{1}{|c|}{ Functionality } & 0.709 \\
\hline $\begin{array}{l}\text { Customer Experential } \\
\text { Aspects }\end{array}$ & 0.824 \\
\hline Kepercayaan & 0.521 \\
\hline Kepuasan Konsumen & 0.678 \\
\hline Loyalitas Konsumen & 0.532 \\
\hline
\end{tabular}

Tabel 2

Validitas Diskriminan

\begin{tabular}{|l|l|l|l|l|l|l|}
\hline Variabel & CE Aspects & Functionality & Kepercayaan & $\begin{array}{l}\text { Kepuasan } \\
\text { Konsumen }\end{array}$ & Kualitas Situs & $\begin{array}{l}\text { Loyalitas } \\
\text { Konsumen }\end{array}$ \\
\hline CE Aspects & & & & & & \\
\hline Functionality & 0.799 & & & & & \\
\hline Kepercayaan & 0.763 & 0.790 & 0.730 & 0.860 & & \\
\hline $\begin{array}{l}\text { Kepuasan } \\
\text { Konsumen }\end{array}$ & 0.627 & 1.143 & 0.831 & 0.733 & & \\
\hline Kualitas Situs & 1.064 & 0.761 & 0.875 & 0.809 & 0.763 & \\
\hline $\begin{array}{l}\text { Loyalitas } \\
\text { Konsumen }\end{array}$ & 0.650 & & & & & \\
\hline
\end{tabular}

\section{Reliabilitas}

Setiap indikator variabel penelitian dalam uji reliabilitas indikator memiliki nilai lebih dari $0.6(>0.6)$. Indikator yang digunakan untuk mengukur variabel dalam penelitian ini sudah reliabel dan dapat diandalkan.

Tabel 3

Reliabilitas Indikator

\begin{tabular}{|l|l|l|l|l|l|l|l|}
\hline \multicolumn{2}{|l|}{ Kualitas Situs } & \multicolumn{2}{l|}{ Kepercayaan } & \multicolumn{2}{l|}{ Kepuasan Konsumen } & \multicolumn{2}{l|}{ Loyalitas Konsumen } \\
\hline WQ1 & 0.892 & T1 & 0.752 & CS1 & 0.870 & CL2 & 0.752 \\
\hline WQ2 & 0.893 & T2 & 0.787 & CS2 & 0.849 & CL3 & 0.685 \\
\hline WQ3 & 0.732 & T3 & 0.642 & CS5 & 0.746 & CL4 & 0.777 \\
\hline WQ4 & 0.913 & T4 & 0.754 & & & CL5 & 0.699 \\
\hline WQ5 & 0.902 & T5 & 0.723 & & & & \\
\hline & & T6 & 0.662 & & & & \\
\hline
\end{tabular}


Tabel 4

Reliabilitas Konsistensi Internal

\begin{tabular}{|l|l|}
\hline \multicolumn{1}{|c|}{ Variabel } & \multicolumn{1}{c|}{ CR } \\
\hline CE Aspects & 0.903 \\
\hline Functionality & 0.879 \\
\hline Kepercayaan & 0.866 \\
\hline Kepuasan Konsumen & 0.863 \\
\hline Kualitas Situs & 0.889 \\
\hline Loyalitas Konsumen & 0.819 \\
\hline
\end{tabular}

Setiap indikator yang digunakan untuk mengukur variabel pada uji reliabilitas konsistensi internal dalam penelitian ini sudah reliabel dan dapat diandalkan karena memiliki nilai lebih besar dari 0.7 .

\section{Multikolinearitas}

Berdasarkan hasil uji, tidak terdapat multikolinearitas antar variabel bebas karena memiliki nilai VIF kurang dari 5.

Tabel 5

Multikolinearitas

\begin{tabular}{|l|l|l|}
\hline Variabel & Nilai & Keterangan \\
\hline $\mathrm{CL}=\mathrm{f}(\mathrm{T}, \mathrm{CS}, \mathrm{WQ})$ & & \\
$\mathrm{T}$ & $\mathrm{VIF}=2.504$ & Tidak ada multikolinearitas \\
$\mathrm{CS}$ & $\mathrm{VIF}=1.976$ & Tidak ada multikolinearitas \\
$\mathrm{WQ}$ & $\mathrm{VIF}=2.085$ & Tidak ada multikolinearitas \\
\hline $\mathrm{CS}=\mathrm{f}(\mathrm{T}, \mathrm{WQ})$ & & \\
$\mathrm{T}$ & $\mathrm{VIF}=1.976$ & Tidak ada multikolinearitas \\
$\mathrm{WQ}$ & $\mathrm{VIF}=1.976$ & Tidak ada multikolinearitas \\
\hline
\end{tabular}

\section{Koefisien Determinasi dan Relevansi Prediksi}

Pada hasil uji $\mathrm{R}^{2}$ terlihat kemampuan yang sedang untuk menjelaskan variabel loyalitas konsumen dan karena nilainya berada antara 0.5 dan 0.75(Hair et al., 2019). Sedangkan pengaruh terhadap kepuasan konsumen memiliki tingkatan kecil karena nilai koefisiensi determinan sebesar 0.494. Selanjutnya hasil uji relevansi prediksi menunjukkan model dianggap relevan untuk mengukur model penelitian yang telah terbentuk sebelumnya dengan baik karenamemiliki nilai $\mathrm{Q}^{2}$ lebih besar daripada 0 (Hair et al., 2011).

Tabel 6

Koefisien Determinasi dan Relevansi Prediksi

\begin{tabular}{|l|l|l|}
\hline \multicolumn{1}{|c|}{ Variabel } & \multicolumn{1}{c|}{$\mathbf{R}^{2}$} & $\mathbf{Q}^{2}$ \\
\hline Loyalitas Konsumen & 0.534 & 0.261 \\
\hline Kepuasan Konsumen & 0.494 & 0.311 \\
\hline
\end{tabular}

\section{Pengujian Hipotesis}


Berdasarkan hasil uji hipotesis, seluruh hipotesis pada penelitian ini didukung karena kurang dari nilai maksimum 0.005 .

Tabel 7

Pengujian Hipotesis

\begin{tabular}{|c|c|c|c|c|}
\hline \multicolumn{2}{|r|}{ Hipotesis } & $\beta$ & P-values & $\mathrm{f}^{2}$ \\
\hline H1 & $\begin{array}{l}\text { Kualitas Situs } \rightarrow \\
\text { Kepercayaan Konsumen }\end{array}$ & 0.703 & 0.000 & 0.976 \\
\hline $\mathrm{H} 2$ & $\begin{array}{l}\text { Kualitas Situs } \rightarrow \text { Kepuasan } \\
\text { Konsumen }\end{array}$ & 0.236 & 0.002 & 0.055 \\
\hline $\mathrm{H} 3$ & $\begin{array}{l}\text { Kualitas Situs } \rightarrow \text { Loyalitas } \\
\text { Konsumen }\end{array}$ & 0.219 & 0.006 & 0.049 \\
\hline $\mathrm{H} 4$ & $\begin{array}{l}\text { Kepercayaan } \rightarrow \text { Kepuasan } \\
\text { Konsumen }\end{array}$ & 0.517 & 0.000 & 0.267 \\
\hline H5 & $\begin{array}{l}\text { Kepercayaan } \rightarrow \text { Loyalitas } \\
\text { Konsumen }\end{array}$ & 0.384 & 0.000 & 0.126 \\
\hline H6 & $\begin{array}{l}\text { Kepuasan konsumen } \rightarrow \\
\text { Loyalitas konsumen }\end{array}$ & 0.219 & 0.007 & 0.052 \\
\hline H7 & $\begin{array}{l}\text { Kepercayaan } \rightarrow \text { Kepuasan } \\
\text { Konsumen } \rightarrow \text { Loyalitas } \\
\text { Konsumen }\end{array}$ & 0.113 & 0.020 & - \\
\hline $\mathrm{H} 8$ & $\begin{array}{l}\text { Kualitas Situs } \rightarrow \\
\text { Kepercayaan } \rightarrow \\
\text { Kepuasan Konsumen } \rightarrow \\
\text { Loyalitas Konsumen }\end{array}$ & 0.080 & 0.023 & - \\
\hline H9 & $\begin{array}{l}\text { Kualitas Situs } \rightarrow \text { Kepuasan } \\
\text { Konsumen } \rightarrow \\
\text { Loyalitas Konsumen }\end{array}$ & 0.052 & 0.045 & - \\
\hline H10 & $\begin{array}{l}\text { Kualitas Situs } \rightarrow \\
\text { Kepercayaan } \rightarrow \\
\text { Loyalitas Konsumen }\end{array}$ & 0.270 & 0.000 & - \\
\hline
\end{tabular}

\section{DISKUSI}

Berdasarkan hasil uji hipotesis pertama, kualitas situs memiliki pengaruh positif terhadap kepercayaan konsumen. Secara praktis hal ini menunjukkan bahwa kualitas situs Tokopedia dinilai responden sudah cukup baik dan dapat bersaing dengan e-commerce marketplace lainnya dan memberikan konsumen rasa percaya untuk menggunakan Tokopedia.

Berdasarkan hasil uji hipotesis kedua, kualitas situs memiliki pengaruh positif terhadap kepuasan konsumen. Secara praktis hal ini menunjukkan bahwa kualitas situs Tokopedia dinilai responden sudah cukup baik dan dapat bersaing dengan e-commerce marketplace lainnya dan membuat konsumen menjadi puas dan merasa melakukan pilihan yang tepat dalam menggunakan situs Tokopedia. 
Berdasarkan hasil uji hipotesis ketiga, kualitas situs memiliki pengaruh positif terhadap kepuasan konsumen. Secara praktis hal ini menunjukkan bahwa kualitas situs Tokopedia dinilai responden sudah cukup baik dan dapat bersaing dengan e-commerce marketplace lainnya dan yang mana menumbuhkan loyalitas terhadap Tokopedia.

Berdasarkan hasil uji hipotesis keempat, kepercayaan memiliki pengaruh positif terhadap kepuasan konsumen. Secara praktis hal ini menunjukkan bahwa responden percaya pada Tokopedia, merasa aman dalam bertransaksi dan menggunakan situs Tokopedia yang membuat konsumen menjadi puas dan merasa melakukan pilihan yang tepat dalam menggunakan situs Tokopedia.

Berdasarkan hasil uji hipotesis kelima, kepercayaan memiliki pengaruh positif terhadap loyalitas konsumen. Secara praktis hal ini menunjukkan bahwa responden percaya pada Tokopedia, merasa aman dalam bertransaksi dan menggunakan situs Tokopedia yang kemudian menumbuhkan loyalitas terhadap Tokopedia.

Berdasarkan hasil uji hipotesis keenam, kepuasan konsumen memiliki pengaruh positif terhadap loyalitas konsumen. Secara praktis hal ini menunjukkan bahwa responden merasa puas terhadap berbagai aspek dan fitur yang tersedia pada Tokopedia, yang kemudian menumbuhkan loyalitas terhadap Tokopedia.

Berdasarkan hasil uji hipotesis ketujuh, kepercayaan memiliki pengaruh positif terhadap loyalitas konsumen melalui kepuasan konsumen. Secara praktis hal ini menunjukkan bahwa responden percaya pada Tokopedia, merasa aman dalam bertransaksi dan menggunakan situs Tokopedia yang mana membuat pengguna menjadi puas dan merasa melakukan pilihan yang tepat yang kemudian menumbuhkan loyalitas terhadap Tokopedia.

Berdasarkan hasil uji hipotesis kedelapan, kualitas situs memiliki pengaruh positif terhadap loyalitas konsumen melalui kepercayaan dan kepuasan konsumen. Secara praktis hal ini menunjukkan bahwa kualitas situs Tokopedia dimata konsumen sudah cukup baik dan dapat bersaing dengan e-commerce marketplace lainnya, yang mana menumbuhkan rasa percaya, rasa puas dan perasaan melakukan pilihan yang tepat, yang kemudian menumbuhkan loyalitas terhadap Tokopedia.

Berdasarkan hasil uji hipotesis kesembilan, kualitas situs memiliki pengaruh positif terhadap loyalitas konsumen melalui kepuasan konsumen. Secara praktis hal ini menunjukkan bahwa kualitas situs Tokopedia dimata konsumen sudah cukup baik dan dapat bersaing dengan e-commerce marketplace lainnya, yang mana menumbuhkan rasa puas dan perasaan melakukan pilihan yang tepat, yang kemudian menumbuhkan loyalitas terhadap Tokopedia.

Berdasarkan hasil uji hipotesis kesepuluh, kualitas situs memiliki pengaruh positif terhadap loyalitas konsumen melalui kepercayaan. Secara praktis hal ini menunjukkan bahwa kualitas situs Tokopedia dimata konsumen sudah cukup baik dan dapat bersaing dengan ecommerce marketplace lainnya, yang mana menumbuhkan rasa percaya dan kemudian menumbuhkan loyalitas terhadap Tokopedia.

\section{PENUTUP}

Berdasarkan hasil penelitian, kualitas situs ditunjukkan memiliki pengaruh positif terhadap kepuasan, kepercayaan, dan loyalitas konsumen. Ketika konsumen merasa kualitas situs sebuah marketplace memadai, maka konsumen akan menjadi percaya, merasa puas dan melakukan pilihan yang tepat, dan akhirnya membentuk loyalitas terhadap perusahaan. 
Kepercayaan juga mempengaruhi kepuasan dan loyalitas konsumen. Ketika konsumen merasa aman dalam menggunakan situs dan melakukan transaksi pada platform tersebut, ia dapat memiliki pengalaman yang memuaskan, yang pada akhirnya menumbuhkan rasa loyal. Pada dasarnya bisa disimpulkan bahwa, jika konsumen dapat merasa percaya dan puas terhadap suatu produk atau jasa, kemungkinan besar ia akan menjadi loyal terhadap brand tersebut.

Kepuasan konsumen memliki pengaruh positif terhadap loyalitas konsumen. Ketika konsumen memiliki pengalaman yang memuaskan, akan tumbuh dalam dirinya rasa loyal yang dimiliki pada sebuah brand.

Keterbatasan yang dimiliki dalam penelitian ini adalah variabel yang digunakan untuk meneliti loyalitas pengguna situs Tokopedia di Jakarta hanya sebatas kualitas situs, kepercayaan dan kepuasan konsumen. Kemudian terdapat juga keterbatasan dalam jumlah pengambilan sampel, dimana peneliti hanya menggunakan 140 sampel dikarenakan keterbatasan waktu dalam pengumpulan sampel.

Untuk penelitian dimasa yang mendatang, disarankan menggunakan variabel lainnya seperti seperti citra merek, kualitas produk serta minat beli, sehingga penelitian ini dapat berkembang dan memiliki manfaat yang lebih. Kemudian dalam penambahan sampel dan perluasan batasan wilayah juga dapat dilakukan agar hasil data yang didapatkan dapat semakin luas dan menggambarkan secara lebih nyata sikap konsumen di Indonesia. Disarankan bagi Tokopedia untuk meningkatkan kualitas situs, karena masih terdapat konsumen yang merasa kurang puas dengan navigasi pada situs. Disarankan pula bagi Tokopedia untuk lebih meyakinkan konsumen bahwa mereka tidak akan menjual informasi personal, karena masih ada beberapa konsumen yang kurang yakin kepada Tokopedia.

\section{DAFTAR PUSTAKA}

Ajzen, I. (1991). The Theory of Planned Behavior. Organizational Behavior and Human Decision Processes, 50: 179-211.

Akhgari, M., Bruning, E. R., Finlay, J., \& Bruning, N. S. (2018). Image, performance, attitudes, trust, and loyalty in financial services. International Journal of Bank Marketing, 36(4), 744-763. https://doi.org/10.1108/ijbm-06-2017-0118

Al-Debei, M. M., Akroush, M. N., \& Ashouri, M. I. (2015). Consumer attitudes towards online shopping. Internet Research, 25(5), 707-733.https://doi.org/10.1108/intr-052014-0146

Chang, C., \& Hung, J. (2018). The effects of service recovery and relational selling behavior on trust, satisfaction, and loyalty. International Journal of Bank Marketing, 36(7), 1437-1454. https://doi.org/10.1108/ijbm-07-2017-0160

Filieri, R., Alguezaui, S., \& McLeay, F. (2015). Why do travelers trust Tripadvisor? Antecedents of trust towards consumer-generated media and its influence on recommendation adoption and word of mouth. Tourism Management, 51, 174185. https://doi.org/10.1016/j.tourman.2015.05.007

Giao, H. N., Vuong, B. N., \& Quan, T. N. (2020). The influence of website quality on consumer's E-loyalty through the mediating role of E-trust and E-satisfaction: An evidence from online shopping in Vietnam. Uncertain Supply Chain Management, 351370. https://doi.org/10.5267/j.uscm.2019.11.004 
Hair, J. F., Ringle, C. M., \& Sarstedt, M. (2011). PLS-SEM: Indeed a silver bullet. The Journal of Marketing Theory and Practice, 19(2), 139-151. https://doi.org/10.2753/MTP1069-6679190202

Hair, J. F., Risher, J. J., Sarstedt, M., \& Ringle, C. M. (2019). When to use and how to report the results of PLS-SEM. European Business Review, 31(1), 2-24. https://doi.org/10.1108/EBR-11-2018-0203

Jeon, M. M., \& Jeong, M. (2017). Customers' perceived website service quality and its effects on E-loyalty. International Journal of Contemporary Hospitality Management, 29(1), 438-457. https://doi.org/10.1108/ijchm-02-2015-0054

Kataria, S., \& Saini, V. (2019). The mediating impact of customer satisfaction in relation of brand equity and brand loyalty. South Asian Journal of Business Studies, 9(1), 6287. https://doi.org/10.1108/sajbs-03-2019-0046

Keni, K., \& Sandra, K. K. (2021). Prediksi customer experience Dan service quality terhadap customer loyalty: Customer satisfaction sebagai variabel mediasi. Jurnal Muara Ilmu Ekonomi dan Bisnis, 5(1), 191. https://doi.org/10.24912/jmieb.v5i1.11196

Kim, S., \& Park, H. (2013). Effects of various characteristics of social commerce (Scommerce) on consumers' trust and trust performance. International Journal of Information Management, 33(2),

$318-$

332. https://doi.org/10.1016/j.ijinfomgt.2012.11.006

Kincl, T., \& Štrach, P. (2012). Measuring website quality: Asymmetric effect of user satisfaction. Behaviour \& Information Technology, 31(7), $\quad$ 647657. https://doi.org/10.1080/0144929x.2010.526150

Limbu, Y. B., Wolf, M., \& Lunsford, D. L. (2011). Consumers' perceptions of online ethics and its effects on satisfaction and loyalty. Journal of Research in Interactive Marketing, 5(1), 71-89. https://doi.org/10.1108/17505931111121534

Madariaga, J.G., Recuero Virto, N., Blasco López, M. F., \& Aldas Manzano, J. (2019). Optimizing website quality: The case of two superstar Museum websites. International Journal of Culture, Tourism and Hospitality Research, 13(1), 1636. https://doi.org/10.1108/ijcthr-06-2018-0074

Malhotra, N. K. (2010). Marketing Research: An applied orientation (6th ed.). Pearson Education.

O'Cass, A., \& Carlson, J. (2012). An E-retailing assessment of perceived website-service Innovativeness: Implications for website quality evaluations, trust, loyalty and word of mouth. Australasian Marketing Journal, 20(1), 2836. https://doi.org/10.1016/j.ausmj.2011.10.012

Omoregie, O. K., Addae, J. A., Coffie, S., Ampong, G. O., \& Ofori, K. S. (2019). Factors influencing consumer loyalty: Evidence from the Ghanaian retail banking industry. International Journal of Bank Marketing, 37(3), 798820. https://doi.org/10.1108/ijbm-04-2018-0099

Özkan, P., Süer, S., Keser, İ. K., \& Kocakoç, İ. D. (2019). The effect of service quality and customer satisfaction on customer loyalty. International Journal of Bank Marketing, 38(2), 384-405. https://doi.org/10.1108/ijbm-03-2019-0096

Putra, T. W., \& Keni, K. (2020). Brand experience, perceived value, brand trust untuk memprediksi brand loyalty: Brand love sebagai variabel mediasi. Jurnal Muara Ilmu Ekonomi dan Bisnis, 4(1), 184. https://doi.org/10.24912/jmieb.v4i1.7759 
Sekaran, U., \& Bougie, R. (2013). Research methods for business: A skill-building approach (6th ed.). Wiley.

Selim, N. I., Zailani, S., Aziz, A. A., \& Rahman, M. K. (2019). Halal logistic services, trust and satisfaction amongst Malaysian 3PL service providers. Journal of Islamic Marketing, ahead-of-print(ahead-of-print). https://doi.org/10.1108/jima-05-2018-0088

Slack, N. J., \& Singh, G. (2020). The effect of service quality on customer satisfaction and loyalty and the mediating role of customer satisfaction. The TQM Journal, 32(3), 543558. https://doi.org/10.1108/tqm-07-2019-0187

Worthington, S., Russell-Bennett, R., \& Härtel, C. (2009). A tri-dimensional approach for auditing brand loyalty. Journal of Brand Management, 17(4), 243253. https://doi.org/10.1057/bm.2009.24 